\title{
TELEDIAGNÓstico DE LESÕES BUCAIS. PROJETO DE INVESTIGAÇÃO DA APLICABILIDADE DA TELEODONTOLOGIA.
}

Renata Seleme POSSEBON, Cleto Mariosvaldo PIAZZETA, André SIMÕES, Allan GIOVANINI, Cassius Carvalho TORRES-PEREIRA

Este estudo objetivou avaliar a aplicabilidade do telediagnóstico na Estomatologia, através do envio de dados e imagens clínicas de lesões bucais, via correio eletrônico, para dois avaliadores à distância. Durante 12 meses foram selecionados 24 casos clínicos de pacientes atendidos em uma Unidade Básica do Sistema Único de Saúde do município de Dr. Ulysses-PR. Os históricos clínicos e as imagens digitais das lesões bucais foram registrados através de fichas eletrônicas e câmera digital de alta resolução, e arquivados em formato "doc" e "jpeg". Na ficha clínica eletrônica, omitia-se o diagnóstico final. Os arquivos foram enviados como anexos de correio eletrônico aos avaliadores, que foram solicitados a propor duas hipóteses diagnósticas para cada lesão. Dos 24 casos que compuseram a amostra, verificou-se acerto diagnóstico por parte dos dois avaliadores em 58,33\%. Em 25\% dos casos apenas um dos avaliadores acertou a hipótese sugerida à distância. Em 16,67\% dos casos nenhum dos avaliadores acertou o diagnóstico. O total de casos onde pelo menos um avaliador acertou uma das hipóteses clínicas foi de 83,33\%. Os resultados sugerem que o telediagnóstico pode ser eficaz no diagnóstico de lesões bucais, sendo que a adoção mínima de dois avaliadores incrementa os índices de acerto diagnóstico. 